\title{
Pengaruh Budaya Belajar Terhadap Hasil Belajar Ketrampilan Komputer Dan Pengelolaan Informasi Siswa Sekolah Menengah Kejuruan Muhammadiyah 1 Padang
}

\author{
Hafiz Nugraha $^{1 *}$ dan Ambiyar ${ }^{2}$ \\ ${ }^{1,2}$ Pasca Sarjana, Fakultas Teknik, Universitas Negeri Padang \\ *Corresponding author, e-mail: toyennugraha@gmail.com
}

\begin{abstract}
Abstrak- Artikel ini bertujuan untuk menghitung tingkat capaian (1) budaya belajar siswa di kelas, (2) hasil belajar Ketrampilan Komputer dan Pengelolaan Informasi (KPPI) siswa setelah mengikuti pembelajaran, dan (3) Pengaruh budaya belajar belajar terhadap hasil belajar KPPI siswa Sekolah Menegaha Kejuruan (SMK) Muhammadiyah I Padang. Metode penelitian yang digunakan deskriptif kuantitatif, populasi sebanyak 351 orang peserta didik, sampel dipilih sebanyak 160 orang dengan teknik proporsional random sampling. Data dikumpulkan dengan angket dan dokumentasi. Analisis data menggunakan teknik deskriptif dan inferesial. Penelitian ini menemukan (1) budaya belajar siswa SMK Muhammadiyah I Padang berada dalam kategori baik, (2) hasil belajar KPPI SMK Muhammadiyah I Padang termasuk kategori cukup baik, dan (3) terdapat pengaruh positif yang signifikan antara budaya belajar terhadap hasil belajar KPPI siswa SMK Muhammadiyah I Padang sebesar 8,8 \%.
\end{abstract}

Kata kunci: budaya belajar, hasil belajar KPPI, siswa SMK

\begin{abstract}
This paper discusses to calculate the level of achievement (1) student learning culture in the classroom, (2) learning outcomes of students after learning, and (3) the influence of learning culture on the learning outcomes KPPI students of SMK Muhammadiyah I Padang. The research method used quantitative descriptive, the population of 351 students, the sample was selected as many as 160 people with proportional random sampling technique. Data were collected by questionnaire and documentation. Data analysis using descriptive and inferesial techniques. This study found (1) the learning culture students of SMK Muhammadiyah I Padang is in good category, (2) the learning result of KPPI SMK Muhammadiyah I Padang pretty good category, and (3) there is a significant positive influence between learning culture on learning result KPPI student of SMK Muhammadiyah I Padang at $8.8 \%$.
\end{abstract}

Keywords: learning culture, learning result of KPPI, SMK student

This is an open access article distributed under the Creative Commons 4.0 Attribution License, which permits unrestricted use, distribution, and reproduction in any medium, provided the original work is properly cited. (C2018 by Author and Universitas Negeri Padang

\section{Pendahuluan}

Pendidikan adalah sutu proses pembudayaan, yaitu menanamkan nilai-nilai dan norma-norma dalam tatanan kehidupan berbangsa dan bernegara, menjadikan manusia menjadi mahkluk yang berbudi luhur, mulia dan berbudaya. Tanpa kebudayaan tidak mungkin lahir suatu kepribadian [1]. Budaya adalah suatu sistem nilai dan kepercayaan yang berinteraksi dengan orang dalam suatu organisasi, struktur organisasi dan sistem kontrol yang menghasilkan norma perilaku [2].
Budaya diperoleh melalui proses pembelajaran oleh seseorang atau sekelompok orang dalam lingkungannya yang dapat berkembang menjadi budaya belajar. Budaya belajar adalah ciptaan manusia yang tampak sebagai perilaku mengenai belajar, digunakan oleh seseorang atau kelompok orang untuk menampakkan tindakan dan perbutan dalam lingkungan sekolah.

Pengembangan budaya belajar di Sekolah Menengah Kejuruan (SMK) sudah sejalan dengan arah kebijakan pendidikan di Indonesia. Hal ini tampak jelas dalam Undang-Undang Nomor 20 
tahun 2003 tentang Sistem Pendidikan Nasional pasal 3 menyebutkan pendidikan nasional bertujuan untuk berkembangnya potensi peserta didik agar menjadi manusia yang beriman dan bertakwa kepada Tuhan Yang Maha Esa, berakhlak mulia, sehat, berilmu, cakap, kreatif, mandiri, dan menjadi warga negara yang demokratis serta bertanggung jawab. Tujuan pendidikan nasional itu menjadi dasar dalam pengembangan budaya belajar. Pengembangan budaya belajar dapat dilakukan melalui pengembangan lingkungan masyarakat sekolah. Para siswa hidup dan berkembang dalam ligkungan sosial masyarakat sekolah, maka pengembangan budaya belajar hanya dapat dilakukan dalam lingkungan sosial masyarakat sekolah yang bersangkutan.

Budaya belajar adalah cerminan mutu kehidupan sekolah yang tumbuh kembngnya berdasarkan semangat dan nilai yang dianut sekolah, lingkungan, suasana, rasa, sifat, dan iklim sekolah yang mampu mengembangkan kecerdasan, keterampilan siswa yang ditampakkan dalam bentuk kerjasama warga sekolah dalam kedisiplinan, tanggung jawab, dan motivasi belajar. Budaya belajar merupakan pandangan hidup yang diakui bersama oleh masyarakat sekolah yang mencakup cara berpikir, perilaku, sikap, nilai yang tercermin baik dalam wujud fisik maupun abtrak, terutama yang berkaitan dengan hasil belajar.

Untuk mendapatkan hasil belajar yang optimal, SMK telah menyusun kurikulum yang terdiri dari mata pelajaran normatif, adaptif, dan produktif. Pencapaian penguasaan keterampilan dalam memenuhi kompetensi siswa. Hasil belajar Ketrampilan Komputer dan Pengelolaan Informasi (KPPI) mengacu kepada Standar Kompetensi Lulusan (SKL) dan Standar Kompetensi Kerja Nasional (SKKNI). Sebagai acuan untuk mengetahui tingkat penguasaan hasil belajar diambil dari nilai ujian KPPI.

Hasil belajar adalah perubahan tingkah laku yang mencakup bidang kognitif, afektif dan psikomotorik [3]. Hasil yang diperoleh setelah mengikuti kegiatan belajar adalah berupa ilmu pengetahuan dan keterampilan pada ranah kognitif, afektif, dan psikomotor. Aspek pada ranah kognitif yang berupa pengetahuan, pemahaman, penerapan, analisis, sintesis, dan evaluasi. Aspek pada ranah afektif yang berupa penerimaan, partisipasi, penilaian dan penentuan sikap, organisasi, dan pembentukan pola hidup. Aspek pada ranah psikomotor yang berupa persepsi, kesiapan, gerakan terbimbing, gerakan terbiasa, gerakan kompleks, penyesuaian pola gerakan, kreativitas.
Perubahan tingkah laku yang terjadi pada diri individu baik berupa kognitif, afektif, dan psikomotor setelah belajar biasanya disebut sebagai hasil belajar, sebagaimana yang dikemukakan oleh [4] bahwa hasil belajar merupakan perubahan prilaku yang diperoleh setelah mengalami aktivitas belajar. [5] mengemukakan bahwa, "Hasil belajar merupakan perubahan yang diharapkan terjadi pada prilaku dan pribadi siswa setelah mengalami dan melalui proses belajar". Senada dengan itu, disampaikan [3] bahwa hasil belajar adalah kemampuankemampuan yang dimiliki siswa setelah menerima pengalaman belajarnya.

Seseorang dikatakan telah berhasil dalam belajar apabila pada dirinya terjadi perubahan tingkah laku dan perubahan tersebut disadarinya dan berlangsung terus menerus.[3] menjelaskan belajar dan mengajar adalah sebagai suatu proses yang mengandung tiga unsur yang dapat dibedakan yaitu tujuan pengajaran pengalaman belajar dan hasil belajar. Hasil belajar peserta didik yang memuaskan akan diperoleh jika pengajar memahami perkembangan ranah kongnitif (kemampuan yang berkenaan dengan pengetahuan, penalaran, atau pikiran), ranah afektif, dan ranah psikomotor [6]. Faktor-faktor dalam penilaian prestasi tersebut adalah tingkat pencapaian, usaha, aspek pribadi dan sosial, serta kebiasaan bekerja [7]

Oleh karena itu, untuk mencapai hasil belajar yang maksimum perlu diperhatikan faktor-faktor yang mempengaruhinya. Faktor faktor tersebut yaitu: faktor internal yang berasal dari dalam dan faktor eksternal yang berasal dari luar. Faktor internal siswa tersebut mencakup fisiologis dan psikologis. Secara fisiologis yang memiliki tubuh yang sehat akan berbeda hasil belajarnya dengan orang yang belajarnya dalam keadaan sakit.

Berdasarkan uraian yang telah dikemukakan di atas, tujuan penelitian ini adalah untuk mendeskripsikan: (1) sejauh mana budaya belajar siswa SMK Muhammadiyah I Padang dalam upaya meningkatkan hasil belajar KPPI?; (2) sejauh mana hasil belajar KPPI siswa SMK Muhammadiyah I Padang?; dan (3) apakah terdapat pengaruh yang signifikan antara budaya belajar dengan hasil belajar KPPI siswa SMK Muhammadiyah I Padang?

\section{METODE}

Penelitian ini menggunakan metode deskriptif kuantitatif dengan pendekatan korelasional, yakni suatu teknik yang dirancang untuk mengetahui seberapa besar pengaruh antara variabel bebas 
dengan variabel terikat. Variable bebas dalam penelitian ini adalah budaya belajar dan variabel terikat hasil belajar KPPI siswa SMK Muhammadiyah I Padang. Populasi penelitian ini adalah siswa SMK Muhammadiyah I Padang kelas $\mathrm{X}$, sebanyak 251 orang. Pengambilan sampel dilakukan dengan teknik proposional random sampling. Sampel dipilih sebanyak 160 orang secara acak.

Alat pengumpul data budaya belajar berupa angket dikembangkan sendiri oleh peneliti model skala Likert dengan langkah-langkah sebagai berikut (1) menyusun kisi-kisi sesuai dengan indikator dari masing-masing variabel. (2) menyusun butir-butir pernyataan berdasarkan indikator masing-masing variabel dan (3) melakukan uji coba, yaitu uji validitas dan uji reliabilitas dengan jumlah responden sebagai ujicoba sebanyak 30 orang. Uji validitas dilakukan dengan analisis korelasi Product Moment Pearson dan uji reliabilitasnya menggunakan rumus Alhpa Cronbach. Dalam pengujian validitas, taraf nyata ditentukan $\alpha=0,05$. Butir pernyataan yang dinyatakan valid, jika koefisien korelasi product moment atau $r$ hitung lebih besar dari $r$ tabel, sesuai taraf nyata yang telah ditentukan. Hasil uji coba menunjukkan bahwa koefisien reliabilitas sebesar 0,94 . Kriteria yang digunakan untuk menetapkan reliabilitas instrumen adalah jika koefisien reliabilitas besar atau sama dengan 0,50 [8]

Analisis data dilakukan, yaitu analisis deskriptif dan inprensial. Analisis deskriptif digunakan untuk menjelaskan skor budaya belajar dan hasil belajar KPPI siswa SMK Muhammadiyah I Padang yang diperoleh membandingkan dengan skor rata-rata pengukuran. Apabila skor budaya belajar di atas skor rata-rata hasil pengukuran, berarti SMK itu mempunyai budaya belajar yang baik. Sebaliknya, apabila skor budaya belajar di bawah skor rata-rata hasil pengukuran, berarti budaya belajar di SMK kurang baik. Hal yang sama, juga dilakukan untuk mengukur hasil belajar KPPI. Selanjutnya, untuk mengukur signifikan atau tidaknya pengaruh antara budaya belajar terhadap hasil belajar KPPI siswa SMK Muhammadiyah I Padang dianalisis dengan regresi.

Persyaratan yang harus dipenuhi sebelum melakukan analisis dan pengujian hipotesis yaitu, (1) uji normalitas, dan (2) uji homogenitas.Teknik yang digunakan untuk melakukan pengujian normalitas yaitu dengan galat taksiran dan dilanjutkan dengan uji Lilliefors, dan untuk pengujian homogenitas varians dilakukan dengan uji Barlett.

\section{HASIl DAN PEMBaHASAN}

\section{Budaya Belajar}

Berdasarkan hasil analisis didapatkan rentang skor empiris dari variabel budaya belajar sebesar 63 dengan skor terendah sebesar 100 dan tertinggi sebesar 163. Setelah dilakukan analisis dengan menggunakan teknik statistik deskriptif diperoleh skor rata-rata sebesar 130,77 simpangan baku sebesar 15,03, median sebesar 130.00, modus sebesar 117. Distribusi frekuensi dari data ini diperoleh kelas interval sebanyak 8 dengan panjang kelas 8 yang digambarkan pada Tabel 1 .

Tabel. 1. Distribusi Frekuensi Skor Budaya Belajar siswa SMK Muhammadiyah I Padang

\begin{tabular}{|c|c|c|c|}
\hline No & Kelas Interval & $\begin{array}{c}\text { Frekuensi } \\
\text { Absolut }\end{array}$ & $\begin{array}{c}\text { Frekuensi } \\
\text { Relatif (\%) }\end{array}$ \\
\hline 1 & $100-107$ & 8 & 5.00 \\
\hline 2 & $108-115$ & 18 & 11.25 \\
\hline 3 & $116-123$ & 28 & 17.50 \\
\hline 4 & $124-131$ & 34 & 21.25 \\
\hline 5 & $132-139$ & 27 & 16.88 \\
\hline 6 & $140-147$ & 20 & 12.50 \\
\hline 7 & $148-153$ & 8 & 5.00 \\
\hline 8 & $154-163$ & 17 & 10.63 \\
\hline & Total & 160 & 100 \\
\hline
\end{tabular}

Berdasarkan Tabel 1, tampak bahwa terdapat $21,25 \%$ jumlah responden memperoleh skor rata-rata, $33,75 \%$ respownden memperoleh skor di bawah harga rata-rata, dan $45,00 \%$ responden memperoleh skor di atas harga rata-rata.

\section{Hasil Belajar KPPI}

Berdasarkan data penelitian untuk skor hasil belajar KPPI diperoleh rentang skor empiris sebesar 40,01 dengan skor terendah sebesar 51.42 dan tertinggi sebesar 91,43. Setelah dilakukan analisis dengan menggunakan teknik statistik deskriptif diperoleh skor rata-rata sebesar 69,60, simpangan baku sebesar 9,18, median sebesar 68,57, modus sebesar 68,57, tingkat capaian responden sebesar 76,12\%. Kelas interval sebanyak 8 dengan panjang kelas 5 distribusi frekuensi sebagaimana tampak pada Tabel 2 .

Tabel 2 Distribusi Frekuensi Skor Hasil belajar KPPI

\begin{tabular}{|c|c|c|c|}
\hline No & Kelas Interval & $\begin{array}{c}\text { Frekuensi } \\
\text { Absolut }\end{array}$ & $\begin{array}{c}\text { Frekuensi } \\
\text { Relatif (\%) }\end{array}$ \\
\hline 1 & $51,42-56,41$ & 13 & 8.13 \\
\hline 2 & $56,42-61,41$ & 18 & 11.25 \\
\hline
\end{tabular}




\begin{tabular}{|c|c|c|c|}
\hline 3 & $61,42-66,41$ & 28 & 17.50 \\
\hline 4 & $66,42-71,41$ & 47 & 29.38 \\
\hline 5 & $71,42-76,41$ & 13 & 8.13 \\
\hline 6 & $76,42-81,41$ & 26 & 16.25 \\
\hline 7 & $81,42-86,41$ & 7 & 4.38 \\
\hline 8 & $86,42-92,41$ & 8 & 5.00 \\
\hline & Total & 160 & 100 \\
\hline
\end{tabular}

Berdasarkan Tabel 2,tampak bahwa terdapat 29,38\% jumlah responden yang memperoleh skor rata-rata, $38,88 \%$ responden memperoleh skor di bawah harga rata-rata, dan $33,75 \%$ responden memperoleh skor di atas harga rata-rata.

Selanjutnya, berdasarkan hasil analisis regresi sederhana terhadap pasangan data penelitian antara variabel bebas X (Budaya belajar) dengan variabel terikat $\mathrm{Y}$ (Hasil Belajar Ketrampilan komputer dan pengelolaan informasi) diperoleh koefisien arah regresi (b) sebesar 0,181 dan konstanta (a) sebesar 45,944. Dengan demikian bentuk hubungan kedua variabel tersebut dapat dinyatakan dengan persamaan regresi $\mathrm{Y}=45,944+$ 0,181X. Hasil uji F digambarkan pada Tabel 3.

Analisis varians seperti yang ditunjukkan pada Tabel 4, dapat disimpulkan bahwa bentuk hubungan antara budaya belajar (X) terhadap hasil belajar KPPI (Y) adalah berarti dan linear, dengan demikian model persamaan regresi ini dapat digunakan untuk memprediksi. Model persamaan regresi ini mengandung arti bahwa apabila budaya belajar ditingkatkan satu skor maka kecenderungan hasil belajar KPPI meningkat sebesar 0,181 skor pada konstanta 45.944.. Model pengaruh budaya belajar (X $\left.\mathrm{X}_{1}\right)$ terhadap hasil belajar KPPI (Y) mempunyai persamaan regresi $\mathrm{Y}=45.944+0,181 \mathrm{X}$ tampak seperti Gambar 1.

Analisis korelasi terhadap pasangan data dari kedua variabel tersebut menghasilkan koefisien korelasi Product Moment sebesar ryl

$=0,296$. Untuk uji keberartian koefisien korelasi dapat sajikan pada Tabel 5.

Berdasarkan Tabel 5 dapat disimpulkan bahwa koefisien korelasi ryl $=0,296$ adalah sangat signifikan. Dengan demikian terdapat hubungan positif antara budaya belajar dengan hasil belajar ketrampilan komputer dan pengelolaan informasi. Ini berarti semakin tinggi budaya belajar, maka semakin tinggi pula hasil belajar ketrampilan komputer dan pengelolaan informasi yang dicapainya.. Dengan koefisien determinasi sebesar 0,088 berarti terdapat $8,8 \%$ varians hasil belajar ketrampilan komputer dan pengelolaan informasi yang dijelaskan oleh variabel budaya belajar.

\section{PEMBAHASAN}

Temuan ini menyimpulkan bahwa terdapat pengaruh positif antara budaya belajar terhadap hasil belajar KPPI. Hal ini berarti semakin baik budaya belajar, maka semakin baik pula hasil belajar KPPI yang diperoleh siswa SMK Muhammadiyah I Padang. Hasil analisis menunjukkan koefisien determinasinya sebesar 0,296. Ini berarti $8,8 \%$ varians hasil belajar KPPI dijelaskan oleh variabel budaya belajar. Artinya dengan budaya belajar yang baik dapat memberi peluang bagi peserta didik untuk meningkatkan kompetensinya.

Berdasarkan temuan ini di mana budaya belajar berpengaruh secara signifikan terhadap hasil belajar KPPI. Oleh karena itu, budaya belajar merupakan salah satu variabel penting yang harus diberikan perhatian untuk meningkatkan hasil belajar KPPI. Upaya peningkatkan hasil belajar KPPI siswa harus dikondisikan oleh sekolah, artinya SMK harus mencerminkan kehidupan sekolah dengan nilai-nilai yang membangun hasil belajar KPPI. Misalnya: (1) Melengkapi fasilitas, sarana-prasarana laboratorium KPPI; (2) disiplin belajar siswaperlu diperhatikan, siswa yang kurang jam belajar harus dipenuhi pada waktu lain; (3) laboratorium sekolah, selalu bersih, komputer selalu siap untuk digunakann dan terawat dengan baik; (4) alat bantu pembelajaran tertata dengan baik; dan (5) siswa harus memakai pakaian praktikum dan memperhatikan keselamatan komputer.

Temuan ini mengemukakan bahwa budaya membaca atau belajar adalah suatu sikap dan tindakan atau perbuatan untuk membaca yang dilakukan secara teratur dan berkelanjutan [9]. Seorang yang mempunyai budaya baca adalah bahwa orang tersebut telah terbiasa dan berproses dalam waktu yang lama di dalam hidupnya selalu menggunakan sebagian waktunya untuk membaca.

Temuan ini juga sejalan dengan "keberhasilan siswa atau mahasiswa dalam mengikuti pelajaran atau kuliah banyak bergantung kepada kebiasaan belajar yang teratur dan berkesinambungan" kebiasaan belajar merupakan salah satu faktor internal yang dapat mempengaruhi hasil belajar siswa Selanjutnya [10-13] mengatakan salah satu faktor yang penting yang mempengaruhi hasil belajar adalah kebiasaan belajar. Kebiasaan belajar bukanlah merupakan bakat alamiah atau pembawaan lahir yang dimiliki siswa sejak kecil. Kebiasaan belajar yang baik dan telahmenjadi budaya tidak dapat dibentuk dalam 
waktu yang pendek, tetapi diperlukan proses ditumbuh kembangkan sedikit demi sedikit, sehingga siswa dikatakan memiliki budata belajar yang baik apabila ia mampu memilih cara-cara belajar yang baik..

Budaya belajar adalah suasana kehidupan siswa bertinteraksi dengan lingkungannya, seperti keluarga di rumah, teman-teman di sekolah, guru, konselor, tenaga kependidikan, dan antara kelompak masyarakat sekolah. Interaksi internal kelompok dan antar kelompok terikat oleh berbagai aturan, norma, moral serta etika bersama yang berlaku disuatu sekolah. Kepemimpinan, keteladanan, keramahan, toleransi, kerja keras, disiplin, kepedulian sosial, kepedulian lingkungan, rasa kebanggaan dan tanggung jawab merupakan nilai-nilai yang dikembangkan dalam budaya belajar.

\section{KeSIMPULAN}

Berdasarkan hasil dan pembahasan, disimpulkan sebagai berikut: (1) budaya belajar siswa SMK Muhammadiyah I Padang berada pada kateegori baik, (2) hasil belajar siswa SMK Muhammadiyah I Padang berada pada kateegori cukup baik, dan (3) Terdapat pengaruh yang signifikan budaya belajar terhadap hasil belajar KPPI siswa SMK Muhammadiyah I Padang. Hal ini berarti bahwa apabila budaya belajar ditingkatkan, maka kecenderungan hasil belajar KPPI siswa akan meningkat. Hasil analisis menunjukkan koefisien determinasinya sebesar 0,88 . Ini berarti $8,8 \%$ varians hasil belajar KPPI dijelaskan oleh variabel budaya belajar.

\section{DAfTAR PUSTAKa}

[1] Tilaar, H.A.R. 2004. Paradigma Baru Pendidikan Nasional, Jakarta: Rineka Cipta.

[2] Tika, Moh. Pabundu 2006. Budaya Organisasi dan Peningkatan Kinerja Perusahaan. Penerbit: Bumi Aksara.

[3] Sudjana, Nana. 2002. Penilaian Hasil Proses Belajar Mengajar. Bandung: PT. Remaja Rosdakarya offset

[4] Anni, Catharina. 2004. Psikologi Belajar. Semarang: UPT MKK UNNES

[5] Makmun, Abin Syamsyudin. 2009. Psikologi Kependidikan. Jakarta: PT Remaja Rosda Karya offset

[6] Dimyati dan Mudjiono. 2009. Belajar dan Pembelajaran. Jakarta : Rineka Cipta

[7] Suharsimi Arikunto. 2002. Evaluasi Pengajaran Edisi Revisi. Jakarta: Rineke Cipta
[8] Gay, L.R. 1985. Educational Evaluation and Measurement. Columbus, Ohio: Carles Publishing Company.

[9] Sutarno, NS. 2006. Perpustakaan dan masyarakat. Jakarta: CV Segung Seto.

[10] Djaaali. 2012. Psikologi Pendidikan. Jakarta: Bumi Aksara

[11] Ahyanuardi A, Hambali H, Krismadinata K. Pengaruh Kompetensi Pedagogik Dan Profesional Guru Sekolah Menengah Kejuruan Pasca Sertfikasi Terhadap Komitmen Guru Melaksanakan Proses Pembelajaran. Invotek: Jurnal Inovasi Vokasional Dan Teknologi. 2018 Jul 4;18(1):67-74.

[12] Hamdani H, Krismadinata K. Kontribusi Kompetensi Dan Persepsi Tentang Supervisi Pembelajaran Terhadap Produktivitas Kerja Guru. Invotek: Jurnal Inovasi Vokasional Dan Teknologi. 2017 Dec 9;17(2):61-6.

[13] Usmeldi U, Krismadinata K. Penerapan Strategi Training Within Industry Dalam Pembelajaran Mengoperasikan Sistem Pengendali Elektromagnetik. Invotek: Jurnal Inovasi Vokasional Dan Teknologi. 2017 Nov 10;17(2):21-6.

\section{BiodataPenulis}

Ambiyar, lahir di Padang Panjang, 13 Februari 1955.Menamatkan pendidikan S1 di FKT IKIP padang tahun 1980, S2 di IKIP Yogyakarta 1980, sedangkan S3 diselesaikan di Universitas negeri Jakarta 2005. Staf pengajar pada Jurusan Teknik Mesin FT UNP sejak tahun 1981- sekarang. 
Tabel 3. ANAVA Untuk Uji Signifikansi dan Linearitas

\begin{tabular}{|c|c|c|c|c|c|c|}
\hline \multicolumn{2}{|c|}{ Model } & Sum of Squares & Df & Mean Square & $\mathrm{F}$ & Sig. \\
\hline 1 & Regression & 1175.449 & 1 & 1175.449 & 15.193 & $.000^{\mathrm{a}}$ \\
\hline & Residual & 12224.079 & 158 & 77.368 & & \\
\hline & Total & 13399.527 & 159 & & & \\
\hline
\end{tabular}

a. Predictors: (Constant), $X$

b. Dependent Variable: Y

Tabel 4. Analisis Varian Coefficients ${ }^{\mathrm{a}}$

\begin{tabular}{|c|c|c|c|c|c|c|}
\hline & \multirow[b]{2}{*}{ Model } & \multicolumn{2}{|c|}{ Unstandardized Coefficients } & $\begin{array}{l}\text { Standardized } \\
\text { Coefficients }\end{array}$ & \multirow[b]{2}{*}{$\mathrm{T}$} & \multirow[b]{2}{*}{ Sig. } \\
\hline & & B & Std. Error & Beta & & \\
\hline \multirow[t]{2}{*}{1} & (Constant) & 45.944 & 6.110 & & 7.520 & .000 \\
\hline & $X$ & .181 & .046 & .296 & 3.898 & .000 \\
\hline
\end{tabular}

Tabel 5. Uji Signifikansi Koefisien Korelasi antara Kreativitas (X1) dengan Hasil Belajar Ketrampilan komputer dan pengelolaan informasi (Y)

\begin{tabular}{|c|c|c|c|c|}
\hline & & & & \\
Model & $\mathrm{R}$ & R Square & Adjusted R Square & $\begin{array}{c}\text { Std. Error of the } \\
\text { Estimate }\end{array}$ \\
\hline 1 & $.296^{\mathrm{a}}$ & .088 & .082 & 8.79588 \\
\hline
\end{tabular}
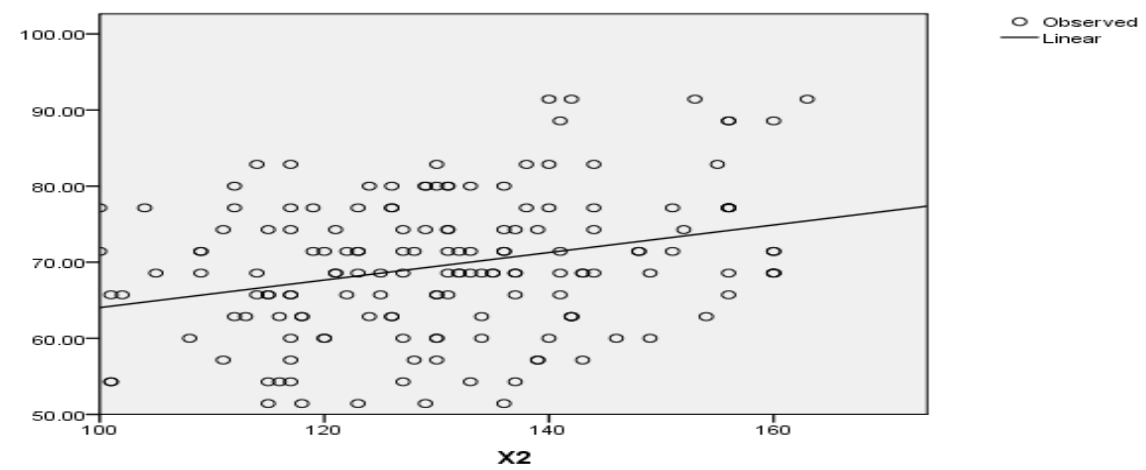

Gambar 1 Model Hubungan antara Budaya Belajar (X) dengan Hasil Belajar Ketrampilan komputer dan pengelolaan informasi $(\mathrm{Y})$ 